\title{
Current Applications of Fibrin Sealant in Urologic Surgery
}

\author{
L. Andrew Evans, Allen F. Morey \\ Urology Service, Brooke Army Medical Center, Fort Sam Houston, Texas, USA
}

\begin{abstract}
Biosurgical preparations designed to promote surgical hemostasis and tissue adhesion are being increasingly employed across all surgical disciplines. Fibrin sealant is the most widely studied and utilized biosurgical adjunct in urology. Complex reconstructive, oncologic, and laparoscopic genitourinary procedures are those most appropriate for sealant use. This article details the diverse urologic applications of fibrin sealant in the management of genitourinary injuries, surgery, and complications.
\end{abstract}

Key words: fibrin sealant; urology; hemostasis; complications; surgery; biologics

Int Braz J Urol. 2006; 32: 131-41

\section{INTRODUCTION}

Although most applications are off-label, tissue sealants and hemostatic agents are being increasingly employed across all surgical disciplines. Biosurgical compounds can serve as adjuncts to primary surgical therapy or may assist in managing or preventing surgical complications. In urology, hemostatic agents and tissue sealants are finding increasing roles in managing traumatic and iatrogenic urologic injuries and promoting optimal wound healing.

Among the variety of hemostatic products now available in the United States (Table-1), fibrin sealant is the most widely utilized biosurgical agent in urologic surgery. This article details the diverse urologic applications of fibrin sealant for hemostasis, tissue adhesion, and urinary tract sealing.

\section{FIBRIN SEALANT}

\section{Development}

Mixtures of coagulation factors have been used in surgery for almost a century, dating back to the use of a fibrin emulsion by Bergel in 1909 to promote wound healing (1). Purified thrombin became available in 1938, and was first combined with fibrinogen in 1944 to enhance adhesion of skin grafts to burned soldiers (2). Although commercial fibrin sealant has been widely used in Europe since the 1970's, concerns about possible viral transmission limited sealant use in the United States until recently. In 1998, Tisseel ${ }^{\circledR}$ (Baxter Healthcare, Deerfield, Illinois) became the first fibrin sealant approved by the Food and Drug Administration (FDA) for use in the United States.

Although the three FDA approved indications for fibrin sealant are reoperative cardiac surgery, colon anastomosis, and treatment of splenic injury, fibrin sealants have been successfully employed in countless numbers of non-urologic surgical applications, including liver laceration, hepatic resection, bowel and vascular anastomoses, enterocutaneous and anorectal fistulae closure, cardiothoracic surgery, and neurosurgery. A review in 2002 by Shekarriz \& Stoller (3) was the first major contemporary urological publication addressing the use of fibrin sealant in uro- 
Table 1 - Hemostatic agents and tissue adhesive available in the United States.

Hemostatic Agents

\section{Component}

Fibrin sealant

Gelatin matrix thrombin

Thrombin

Gelatin sponge

Oxidized cellulose

Collagen sponge

Collagen fleece

Recombinant factor VIIa

Fibrin sealant

Polyethylene glycol

Cyanoacrylate

\section{Brand Name}

Tisseel VH ${ }^{\circledR}$ Crosseal ${ }^{\circledR}$

FloSeal ${ }^{\circledR}$

Thrombin-JMI®

Gelfoam ${ }^{\circledR}$

Surgicel ${ }^{\circledR}$

Actifoam ${ }^{\circledR}$

Avitene ${ }^{\circledR}$

NovoSeven ${ }^{\circledR}$

\section{Tissue Adhesives}

Tisseel VH ${ }^{\circledR}$ Crosseal ${ }^{\circledR}$

CoSeal®

Dermabond $\AA$

\section{Manufacturer}

Baxter Healthcare Omrix

Baxter Healthcare

Jones Pharma

Pharmacia Upjohn

Ethicon

CR Bard

CR Bard

Novo Nordisk A/S

Baxter Healthcare Omrix

Baxter Healthcare

Ethicon logic surgery, and an increasing number of urological sealant applications have followed.

\section{Composition}

Fibrin sealant contains 2 major components (thrombin and highly concentrated fibrinogen) which replicate and augment the final stage of the coagulation cascade - the cleavage of fibrinogen into fibrin by the action of thrombin-when mixed together. It is important to note that the fibrinogen concentration of sealant is supraphysiologic, 15 to 25 times higher than that of circulating plasma. The resultant clot tends to form more rapidly and more reliably than normal. Other key components of fibrin sealant are Factor XIII, which covalently crosslinks the fibrin polymer to produce an insoluble fibrin coagulum, and an antifibrinolytic agent which inhibits fibrinolysis thus preserving the stable fibrin clot (Figure-1).

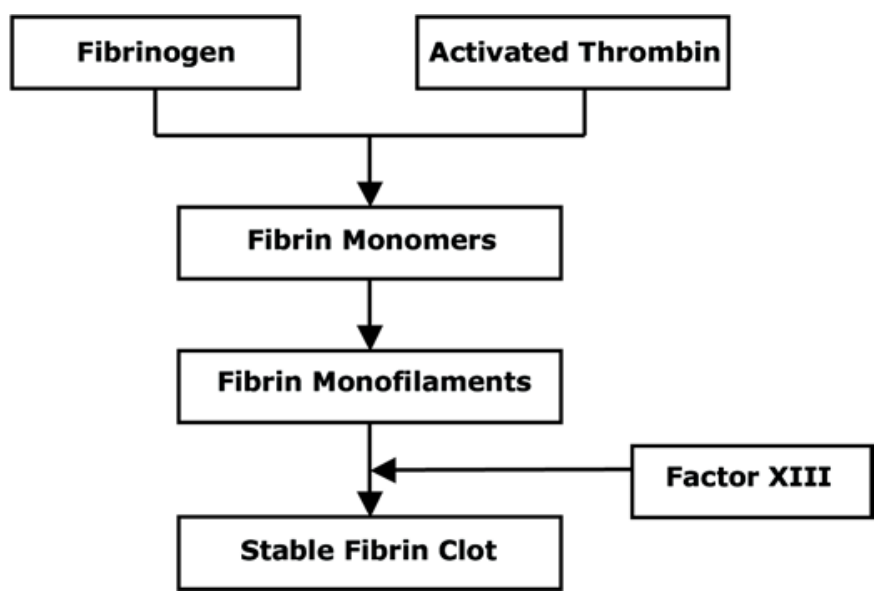

Figure 1 - Mechanism of action of liquid fibrin sealant in recapitulating the terminal portion of the coagulation cascade. 
Tisseel® (Baxter Healthcare, Deerfield, Illinois) and Crosseal ${ }^{\circledR}$ (Omrix Biopharmaceuticals, Ltd, Israel) are the two fibrin sealants currently marketed in the United States. Tisseel ${ }^{\circledR}$ contains bovine aprotinin as its antifibrinolytic agent. Aprotinin is a serine protease inhibitor derived from bovine lung that works to limit fibrinolysis by inhibiting plasmin, kallikrein, and trypsin. Crosseal utilizes only human-derived proteins by including tranexamic acid as its antifibrinolytic agent instead of bovine aprotinin. Tranexamic acid is a synthetic analogue of the amino acid lysine and competes for lysine binding sites on plasminogen and plasmin, preventing binding to fibrin and inhibiting fibrinolysis (4).

\section{Safety}

All approved fibrin sealant preparations utilize a combination of donor screening, serum testing and retesting after 90 days storage, and a two-step vapor heating process to ensure viral safety $(5,6)$. These steps are highly effective in ensuring viral safety and, to our knowledge, there are in 2005 still no reported transmissions of blood-borne viral pathogens associated with the use of FDA approved fibrin sealants (5). One parvovirus B19 transmission involving a non-FDA approved fibrin sealant was reported from Japan, but most adults have preexisting antibodies to this virus and the infection is usually a selflimited diarrhea (7).

\section{Delivery Methods}

Fibrin sealants are administered using a dualchamber delivery system in which one chamber containing fibrinogen and factor XIII is admixed with the other chamber containing thrombin directly at the site of application using a "Y" adaptor, allowing an immediate conversion of fibrinogen to fibrin as the solutions exit the syringe. Dual lumen catheters ensure smooth, rapid sealant delivery, and a variety of specialized catheters and cannulae are available for endoscopic, laparoscopic, and open surgical application. We have also successfully used a dual lumen peripherally inserted central catheter (PICC) line for percutaneous transrenal application (8). Polymerization into the biocompatible fibrin clot is completed within 3 minutes (9), and the clot is gradually broken down and removed from the site by macrophages within 2-4 weeks, eventually becoming histopathologically invisible, without fibrosis or foreign-body reaction (10).

\section{UROLOGICAL APPLICATIONS}

Commercial fibrin sealant is employed for three major reasons in urologic surgery - as a hemostatic agent, a urinary tract sealant, and/or a tissue adhesive. A list of the most common urological applications is presented in Table-2. Fibrin sealant's unique properties as a hemostatic agent, urinary tract sealant, and tissue adhesive make it an effective adjunct for managing complex urologic injury and promoting wound healing in the genitourinary tract.

Table 2 - Urological applications of fibrin sealant.

\section{Hemostasis}

Partial nephrectomy

Open

Laparoscopic (13-16)

Percutaneous nephrolithotomy (22)

Management of splenic injury (23)

Hemophilia and other coagulopathy (24)

Circumcision (25)

Hemorrhagic cystitis (27)

\section{Urinary Tract Sealant}

Laparoscopic and open pyeloplasty (31-34)

Ureteral anastomoses (31-34)

Urethral reconstruction (37)

Simple retropubic prostatectomy (35)

Radical retropubic prostatectomy (36)

Bladder injury (24)

Lymphadenectomy $(38,39)$

Percutaneous nephrolithotomy tract closure (22)

\section{Tissue Adhesion}

Fournier's gangrene reconstruction $(41,42)$

Fistula closure $(24,45,46)$

Skin grafting (42)

Complex urethroplasty (37) 


\section{Hemostasis}

\section{Partial Nephrectomy}

Fibrin sealant has been used since 1979 in open partial nephrectomy (11). The recent advent of minimally invasive techniques for nephron sparing surgery has resulted in widespread fibrin sealant use during laparoscopic partial nephrectomy today (12-15). A recent survey of 193 members of the World Congress of Endourology discovered $68 \%$ of surgeons routinely utilized fibrin sealant to assist with hemostasis during laparoscopic partial nephrectomy (16). Application of fibrin sealant to the cut surface of the renal parenchymal wound after segmental vascular and collecting system suture ligation during partial nephrectomy enhances hemostasis. The fibrin sealant layer can then be supported by a gelatin or collagen bolster, which is effectively glued into the renal defect by holding manual pressure on the bolster "sandwich". In vivo testing of fibrin sealant in a porcine model of open partial nephrectomy demonstrated supra-physiological sealing pressures of the renal parenchymal vasculature (mean $378 \mathrm{~mm} \mathrm{Hg}$ ) and collecting system (mean $166 \mathrm{~mm} \mathrm{Hg}$ ) compared to unsealed controls (17).

\section{Renal Trauma}

In 1989, Kram and colleagues first reported fibrin sealant use in 14 patients with traumatic renal injuries: renal salvage was achieved in all cases with no postoperative infection, delayed hemorrhage, or urinoma formation (18). In 2004, our laboratory reported the effective use of FDA-approved fibrin sealant in central porcine renal stab wounds when used in conjunction with a bolster of absorbable gelatin sponge or microfibrillar collagen (19). Though not yet commercially available, the absorbable fibrin adhesive bandage (AFAB), a similar product consisting of dry fibrin sealant on a polyglactin mesh backing developed in conjunction with the American Red Cross, significantly reduced bleeding in addition to operative and ischemic times in repair of porcine models of lower renal pole amputation (20) and grade IV renal stab wounds (21).

\section{Miscellaneous Hemostatic Applications}

Noller et al. reported no hemorrhagic complications in 10 consecutive renal units treated with fibrin sealant-assisted tubeless percutaneous nephrolithotomy (PCNL) (22). The instillation of 2 to $3 \mathrm{~mL}$ of fibrin sealant into the parenchymal defect is performed as the sheath is removed at the conclusion of PCNL in lieu of nephrostomy drainage. Postoperative computed tomography has confirmed the absence of perirenal hematomas in these "tubeless" procedures.

We have found that intraoperative splenic injury during left nephrectomy is easily managed with direct application of fibrin sealant to the bleeding parenchyma, thereby promoting prompt hemostasis and avoiding the need for splenectomy (23). Fibrin sealant has also been successfully used to control "medical" bleeding caused by warfarin use or other coagulopathies during urologic surgical procedures $(24,25)$. Other urologic hemostatic applications include sealing the oral mucosal donor site during buccal graft urethroplasty (26) and cystoscopic application of fibrin sealant after fulguration to provide hemostasis in refractory radiation-induced hemorrhagic cystitis after supravesical urinary diversion (27).

\section{Urinary Tract Sealant}

A variety of non-urological studies has suggested the increased strength of sealed anastomoses. Skin sutures supported by a layer of fibrin sealant provided watertight anastomoses immediately after surgery and withstood significantly higher hydrostatic pressures than non-sealed anastomoses (28). Han et al. noted that microvascular sutured anastomoses supported by fibrin sealant had enhanced reendotheliazation (29), and Park et al. reported significantly increased tensile strength in sealed skin closure versus controls (30).

\section{Ureteral Anastomosis}

Kram and colleagues first reported the successful use of fibrin sealant as a bolster over the suture line for ureteral anastomosis in 1989 (18). We have found fibrin sealant to be a useful adjunct in managing a variety of ureteral injuries, both iatrogenic and traumatic, and have frequently performed 
"drain-free" sealed repairs. Between 2001 and 2003, 10 patients underwent definitive management of ureteral injury at our institution. Our experience has shown that sealant effectively prevents ureteral urinary extravasation and has not been associated with postoperative infection, leak, or scar formation (Figure-2). We believe that a sealed, stented ureteral repair is prudent in cases where a transabdominal approach has been performed because transabdominal drains are avoided. We also feel it is important to ap-
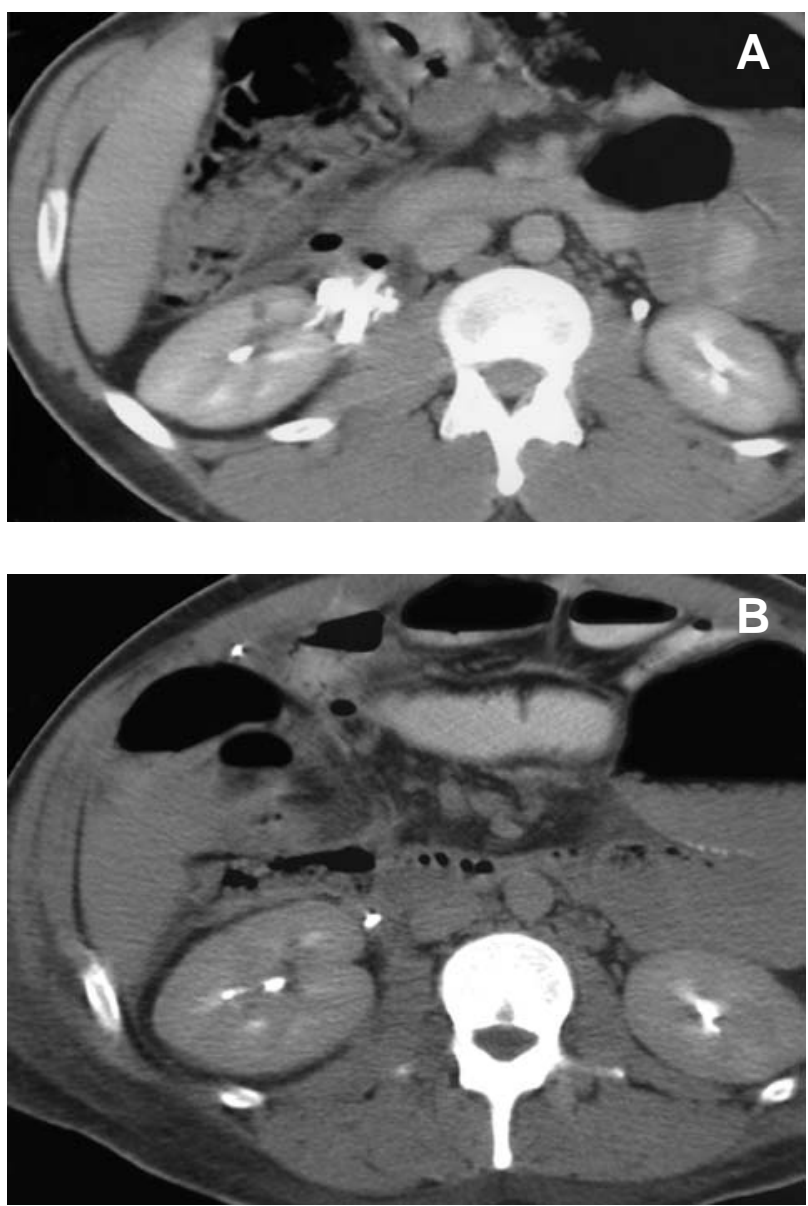

Figure $2-A)$ Stab wound to right flank with medial perirenal contrast material extravasation on preoperative trauma computed tomography $(C T)$. A $4 \mathrm{~cm}$ laceration to the right renal pelvis was successfully repaired using 5-O PDS suture with the application of a bolster of $5 \mathrm{cc}$ of fibrin sealant over the suture line to reinforce urinary tract seal. No drain was placed. B) Postoperative $C T$ image obtained 72 hours later demonstrates drain-free intact repair over ureteral stent without evidence of extravasation or urinoma. ply the sealant as a means of "suture support" by reinforcing standard suture lines, not in lieu of careful suture repair.

The increasing performance of laparoscopic renal reconstruction surgery may lead to increased sealant use. Fibrin sealant has been shown to successfully support approximating sutures in a porcine model of laparoscopic ureteral anastomoses (31) and has improved radiographic outcomes compared to free needle suturing and laser weld closure (32). A variety of studies have shown fibrin sealant to be effective as a bolster for laparoscopic pyeloplasty or collecting system repair (33), and satisfactory drainage has been confirmed by radiologic imaging at one to two years (34).

\section{Prostatectomy}

Drain-free simple retropubic prostatectomy has been successfully performed in over 25 cases in our institution, and we have demonstrated a faster return to regular diet and shortened hospital stay when compared with conventional simple prostatectomy (35). Again, we believe it is important to apply the sealant outside the urinary tract, over the sutured prostatic capsular closure, to ensure that the fibrin clot does not occlude urinary catheter drainage. Similarly, Diner et al. reported in 2004 that a significant decrease in postoperative drain output was noted in 16 patients following radical retropubic prostatectomy when $5 \mathrm{cc}$ of fibrin sealant was applied to the suture line of the urethrovesical anastomosis (36). Earlier drain removal should facilitate a more expedient recovery and earlier discharge from the hospital leading to cost savings.

\section{Urethroplasty}

Fibrin sealant appears to allow earlier catheter removal, improved patient satisfaction, and enhanced wound healing after pendulous urethroplasty (37). In our experience of applying fibrin sealant directly over a suture line of 5-zero polydiaxanone during pendulous urethroplasty in 18 patients, a completely healed anastomosis was confirmed by voiding cystourethrography (VCUG) performed 1 week postoperatively in $83 \%$ of patients; all 18 patients demonstrated complete healing within 14 days, com- 
pared to $8 \%$ of patients in the control group who had persistent extravasation at 21 days postoperatively ( $\mathrm{p}$ $<0.05$ ). Pendulous urethral reconstruction seems to be uniquely well-suited for sealant use because the superficial nature of the urethra in this location does not provide the robust surrounding spongy tissues that are routinely found in the bulbar urethra (Figure-3).

\section{Complication Management}

Fibrin sealant appears to promote the successful transvaginal management of iatrogenic cystotomy sustained during transvaginal hysterectomy. We observed that direct transvaginal fibrin sealant injection functions well as a bolster interposition over the cystotomy repair, thus preventing the additional time and morbidity required for abdominal bladder repair or tissue interposition with a Martius or omental flap (24). Fibrin sealant has also been utilized to prevent lymphocele formation after lymphadenectomy (38). Used as a sclerosant after percutaneous drainage of postoperative lymphoceles in renal transplantation, instillation of fibrin sealant achieved complete resolution of the lymphocele in $75 \%$ of patients without the need for open surgical management (39). Percutaneous transrenal application of $5 \mathrm{cc}$ of fibrin sealant across a refractory calyceal urinary leak secondary to gunshot wound has proven effective in sealing refractory collecting system injury (8).

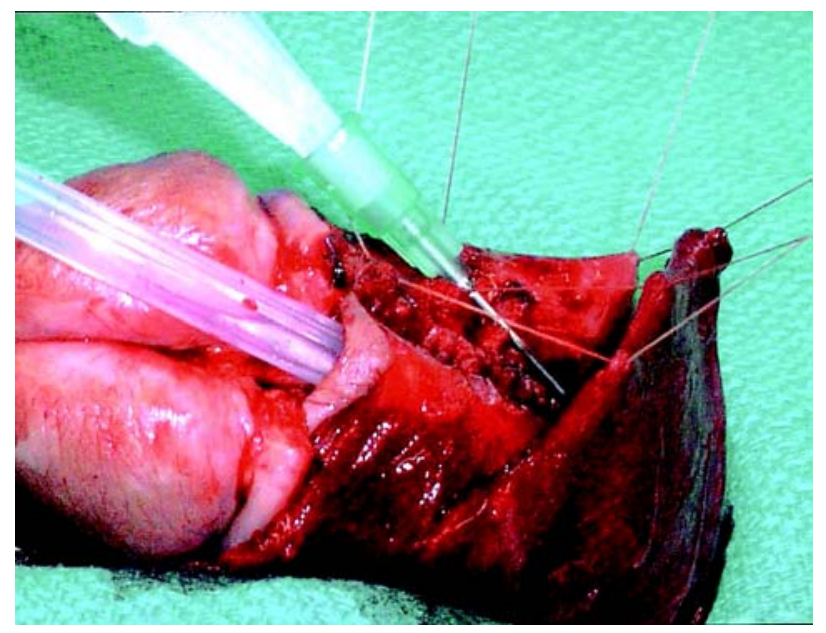

Figure 3 - Application of fibrin sealant as a bolster over the suture line of pendulous urethroplasty. Redundant tunica dartos pedicle is glued in place over suture line.

\section{Tissue Adhesion}

\section{Tissue Planes}

The fibrin polymer resulting from fibrin sealant application facilitates wound healing by increasing tissue plane adherence, thus eliminating dead space, accelerating revascularization, reducing hemorrhage, preventing seroma, and minimizing inflammation (40).

Tissue sealant properties of fibrin sealant have been applied to reduce air leaks and bronchopleural fistulae after pulmonary resection and decortication, secure skin grafts in reconstructive and burn surgery, and occlude chronic enterocutaneous and anorectal fistulous tracts.

Fibrin sealant is now routinely used at our institution during complex urethroplasty, especially cases requiring panurethral reconstruction (Figure4). The scrotum is completely bivalved to provide wide access to the underlying diseased urethra, and the scrotal wings are glued together with sealant after urethral repair to prevent edema and hematoma. Similar efficacy has been reported in 17 patients undergoing complex genital reconstructive surgery such as spit-thickness skin grafting and thigh flap surgery for Fournier's gangrene sequelae and invasive penile cancer: $94 \%$ of patients recovered without infection, seroma, hematoma, or other complications (Figure5) $(41,42)$.

\section{Urinary Tract Fistulae}

In addition to sealing tissue planes, fibrin sealant promotes closure of urinary fistulae by promoting the local proliferation of fibroblasts and subsequent replacement by connective tissue, allowing for occlusion of the fistulous tract (6). The fibrin polymer promotes the ingrowth of fibroblasts during wound healing and an influx of immune cells is stimulated in a paracrine fashion (43). The complex interaction of neutrophils, macrophages, and fibroblasts provides the basis of wound contraction and remodeling necessary for healthy wound healing. The recent application of the Vacuum Assisted Closure ${ }^{\circledR}$ (VAC®, Kinetic Concepts, Inc., San Antonio, Texas) device in closing larger complex wounds is believed to function through similar cellular mechanisms (44). 

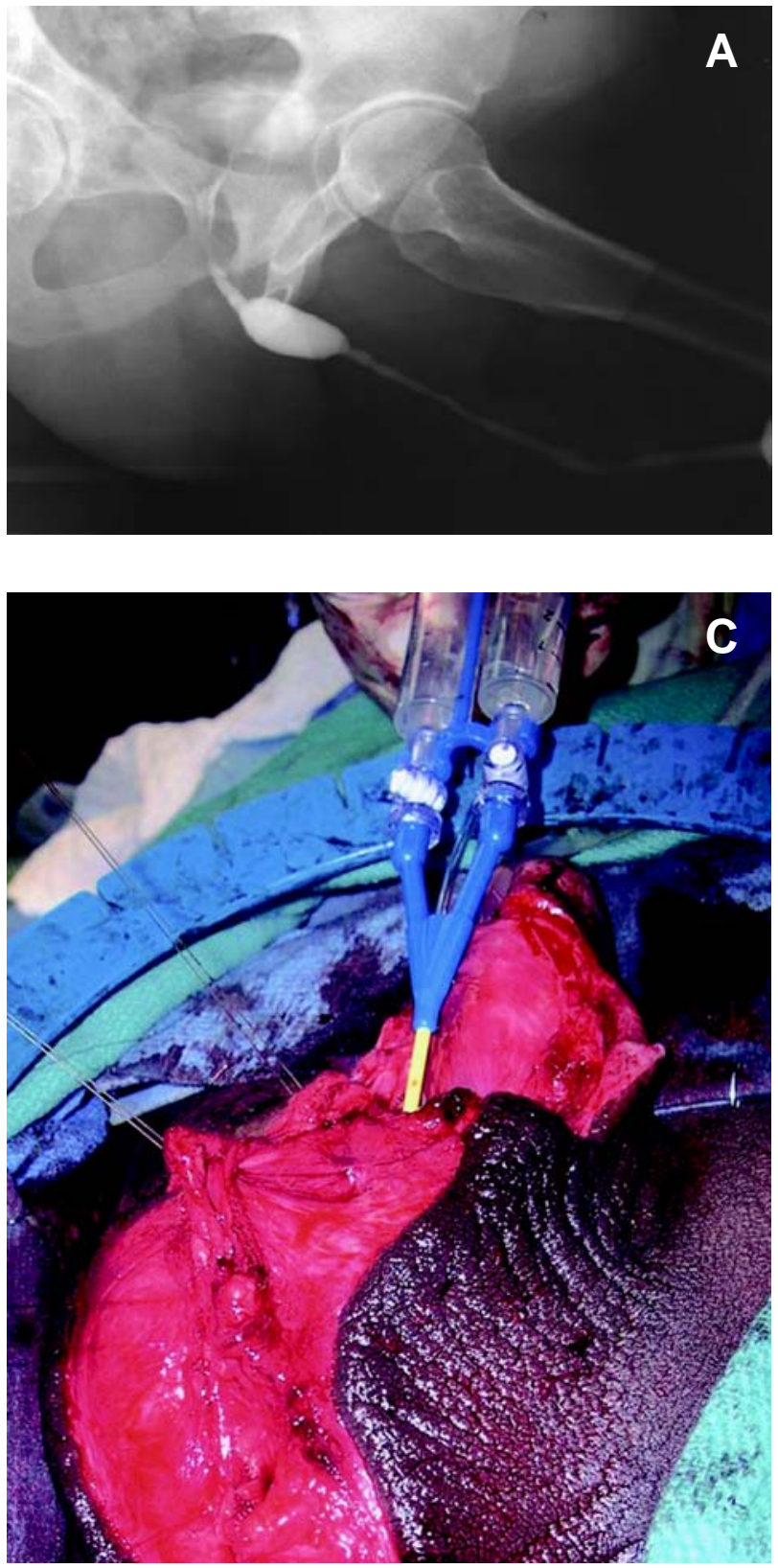

Figure 4 - Panurethral reconstruction. A) Preoperative retrograde urethrogram shows extensive urethral stricture. B) Penile base, scrotum, and perineum are completely bivalved, thus allowing excellent exposure for urethral reconstruction. Buccal grafts were required in this case to reconstruct a $17 \mathrm{~cm}$ defect. Fibrin sealant is applied as a bolster to the suture lines and as a tissue adhesive to glue the scrotal wings back together with good hemostasis. C) Application of fibrin sealant to glue scrotal wings together after urethral reconstruction. D) Postoperative result after scrotum is glued and sutured back together shows no ecchymosis, edema, or drain requirement.
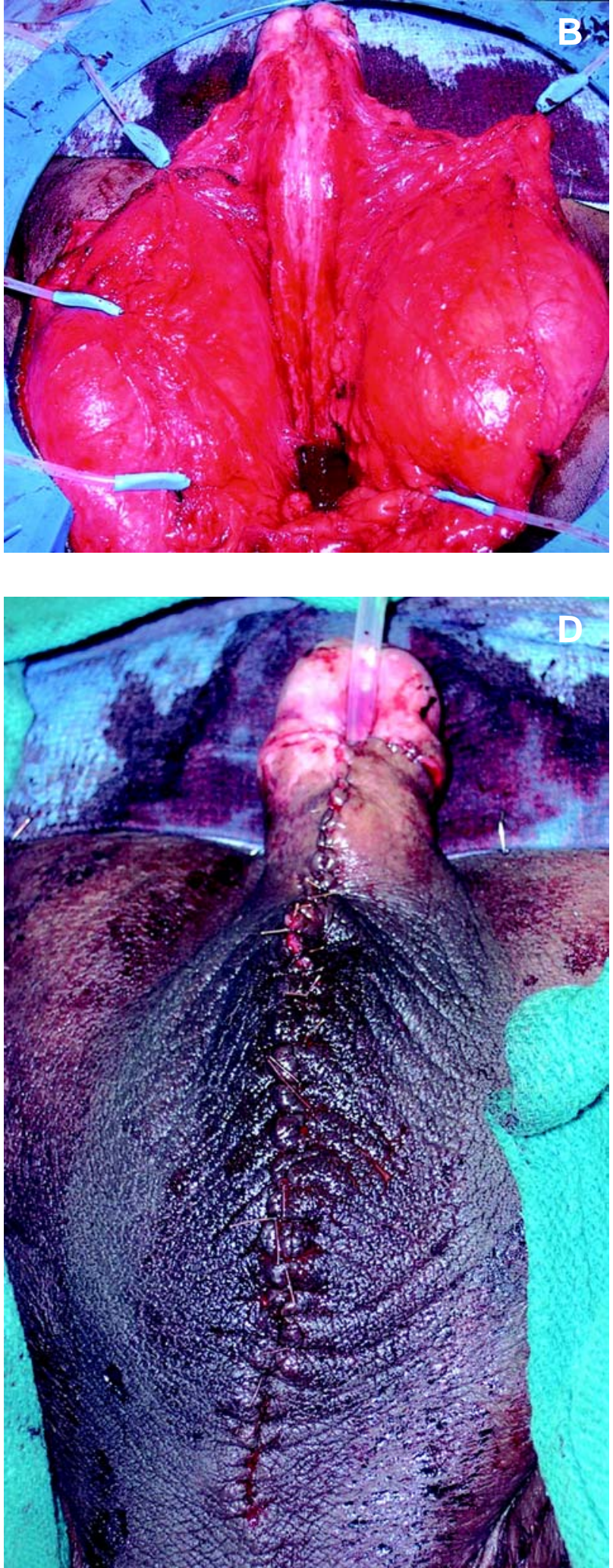

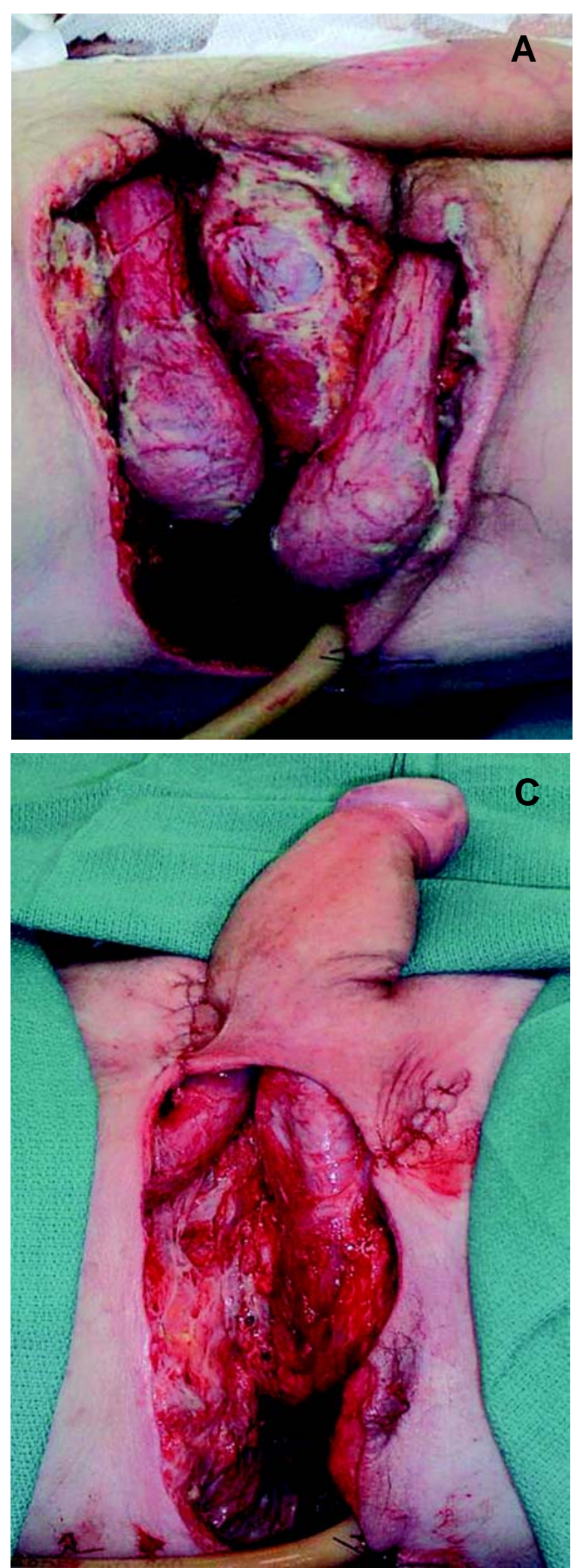
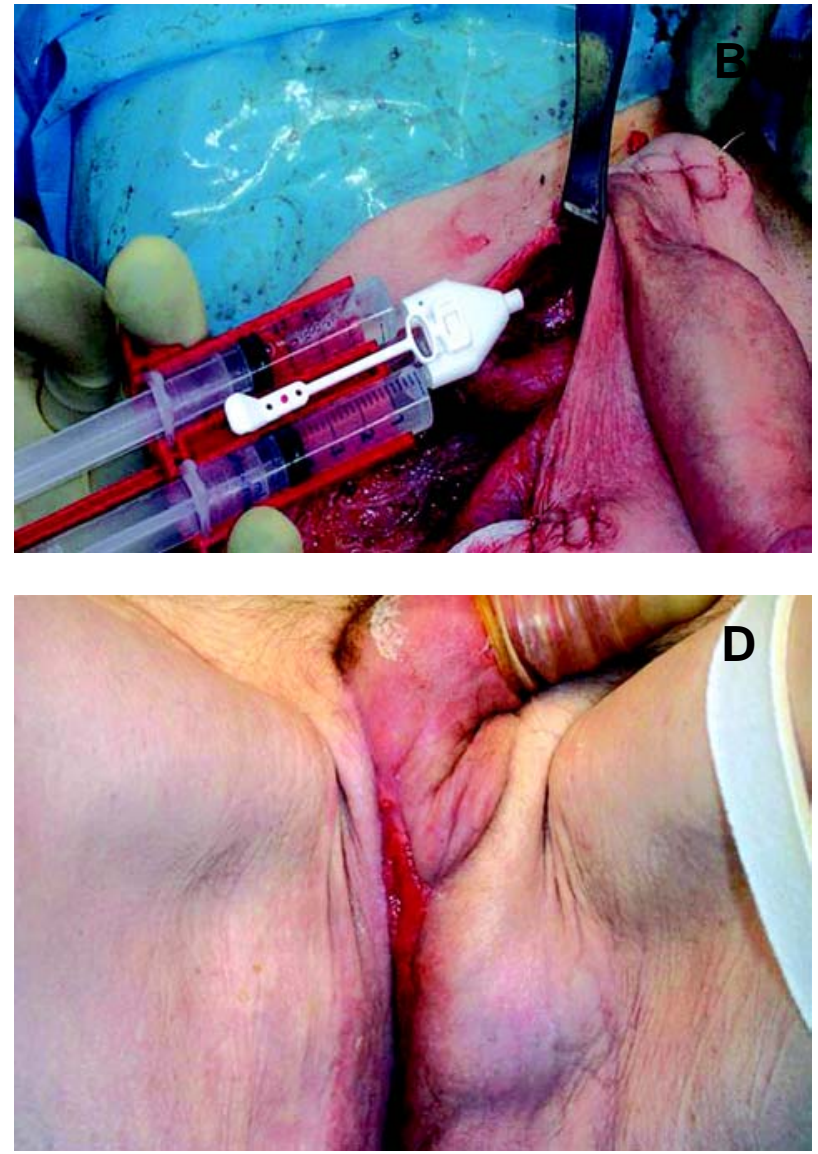

Figure 5 - Successful Fournier's gangrene reconstruction assisted by fibrin sealant. A) Genital wound after initial debridement for extensive perirectal necrotizing infection with extensive scrotal involvement. B) Lateral view of same patient after second debridement showing application of aerosolized fibrin sealant sprayed under local tissue flaps to enhance adherence, hemostasis, and promote wound healing. C) Final appearance immediately after secondary debridement shows surrounding skin flaps mobilized to shrink the tissue defect, glued into place with fibrin sealant. Catheter is in presacral cavity in area where necrotic rectum had previously been. D) Final appearance after wound vac assisted closure 2 months postoperatively. No grafts or additional skin flaps were used to provide skin coverage. Testes are still buried in thigh pouches.

Morita and Tokue reported the successful closure of a radiation-induced vesicovaginal fistula with the endoscopic injection of fibrin sealant in combination with bovine collagen (45). Three serial injections of fibrin sealant allowed for complete continence in the case of an ureterocutaneous fistula following cadaveric kidney transplantation (46). We reported 
the successful definitive treatment of 6 cases of vesicocutaneous and urethrocutaneous fistulae by sealing the tract with the direct injection of $5 \mathrm{cc}$ commercial fibrin sealant in conjunction with open or endoscopic fulguration (24) (Figure-6). We have not found sealant to be effective in vesicovaginal fistula, however, and this is probably because these fistulas are too short and broad compared with the long, thin fistulas typically found extending from the lower urinary tract in males.

\section{SAFETY CONSIDERATIONS}

Fibrin sealant should not be placed into large blood vessels due to the risk for potential thromboembolism. Repeat use of bovine thrombin preparations, which also contain bovine factor $\mathrm{V}$, can induce the formation of antibodies that cross-react with human factor V and lead to a coagulopathic state (47). Pavlovich reported the postoperative development of coagulopathy due to repeat exposure to bovine thrombin during partial nephrectomy (48). The use of bovine-derived proteins carries a risk of allergic reaction upon re-exposure to the material, although bovine aprotinin (found in fibrin sealant) is much less immunogenic than thrombin (49). The reported incidence of hypersensitivity to intravenous aprotinin approaches $10 \%$; thus, fibrin sealant containing bovine protein products should be used with caution in patients previously exposed to aprotinin (50).

\section{CONCLUSIONS}

Hemostatic agents and tissue sealants should not be viewed as a replacement for conventional sound surgical judgment or technique, but rather as complementary adjuncts to improve surgical outcome. Fibrin sealant offers an effective adjunct for hemostasis, reinforcement of urinary tract closure, and adhesion of tissue planes. Numerous reports in virtually all surgical disciplines have confirmed the reliable enhancement of wound healing promoted by fibrin sealant. Future development of novel biotherapeutic materials will continue to provide urologists with safe,
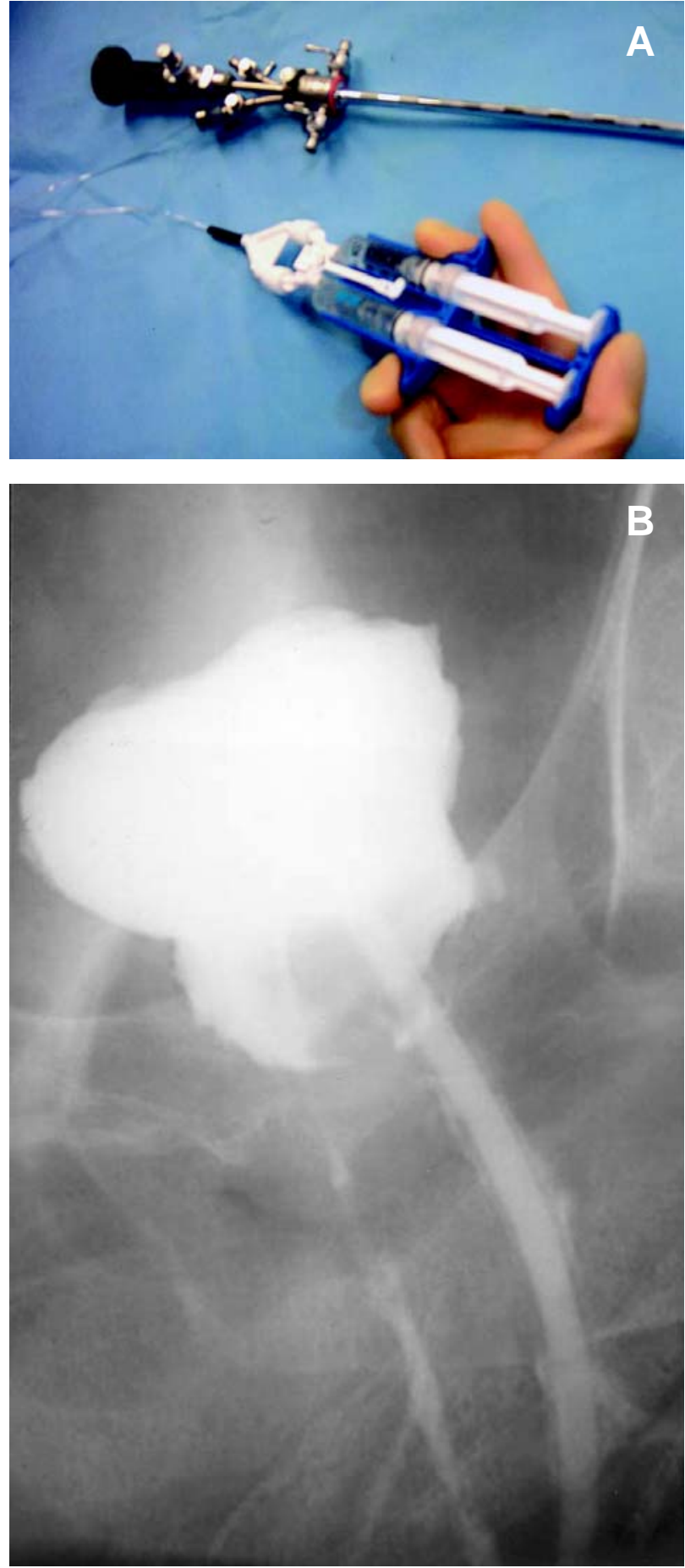

Figure 6 - A) Cystoscopic injection via dual lumen catheter with " $Y$ " adapter is one of several available devices for application of fibrin sealant. B) In this case, sealant was delivered cystoscopically to close a urethrocutaneous fistula after endoscopic fulguration. 
reliable agents for managing challenging urogenital injuries and complications.

\section{DISCLAIMER}

The views expressed in this article are those of the authors and do not reflect the official policy or position of the Department of Defense or other departments of the U.S. Government.

\section{CONFLICT OF INTEREST}

None declared.

\section{REFERENCES}

1. Bergel S: Uber Wirkungen des Fibrins. Dtschr Med Wochenschr. 1909; 35: 633-65.

2. Cronkite EP, Lozner EL, Deaver J: Use of thrombin and fibrinogen in skin grafting. JAMA. 1944; 124: 976-8.

3. Shekarriz B, Stoller ML: The use of fibrin sealant in urology. J Urol. 2002; 167: 1218-25.

4. Dunn CJ, Goa KL: Tranexamic acid: a review of its use in surgery and other indications. Drugs. 1999; 57: 1005-32.

5. Jackson MR: Fibrin sealants in surgical practice: An overview. Am J Surg. 2001; 182: S1-S7.

6. Spotnitz WD: Commercial fibrin sealants in surgical care. Am J Surg. 2001; 182: 8S-14S.

7. Hino M, Ishiko O, Honda KI, Yamane T, Ohta K, Takubo T, et al.: Transmission of symptomatic parvovirus B19 infection by fibrin sealant used during surgery. Br J Haematol. 2000; 108: 194-5.

8. Baughman SM, Morey AF, Van Geertruyden PH, Radvany MG, Benson AE, Foley JP: Percutaneous transrenal application of fibrin sealant for refractory urinary leak after gunshot wound. J Urol. 2003; 170: 522-3.

9. Sapala JA, Wood MH, Schuhknecht MP: Anastomotic leak prophylaxis using a vapor-heated fibrin sealant: report on 738 gastric bypass patients. Obes Surg. 2004; 14: 35-42.

10. Martinowitz U, Saltz R: Fibrin sealant. Curr Opin Hematol. 1996; 3: 395-402.

11. Urlesberger H, Rauchenwald K, Henning K: Fibrin adhesives in surgery of the renal parenchyma. Eur Urol. 1979; 5: 260-1.
12. Wolf J, Seifman B, Montie J: Nephron sparing surgery for suspected malignancy: Open surgery compared to laparoscopy with selective use of hand assistance. J Urol. 2000; 163: 1659-64.

13. Janetschek G, Daffner P, Peschel R, Bartsch G: Laparoscopic nephron sparing surgery for small renal cell carcinoma. J Urol. 1998; 159: 1152-5.

14. Pruthi RS, Chun J, Richman M: The use of a fibrin tissue sealant during laparoscopic partial nephrectomy. BJU Int. 2004; 93: 813-7.

15. Finley DS, Lee DI, Eichel L, Uribe CA, McDougall EM, Clayman RV: Fibrin glue-oxidized cellulose sandwich for laparoscopic wedge resection of small renal lesions. J Urol. 2005; 173: 1477-81.

16. Gerber GS, Stockton BR: Laparoscopic partial nephrectomy. J Endourol. 2005; 19: 21-4.

17. Kouba E, Tornehl C, Lavelle J, Wallen E, Pruthi RS: Partial nephrectomy with fibrin glue repair: measurement of vascular and pelvicaliceal hydrodynamic bond integrity in a live and abbatoir porcine model. J Urol. 2004; 172: 326-30.

18. Kram HB, Ocampo HP, Yamaguchi MP, Nathan RC, Shoemaker WC: Fibrin glue in renal and ureteral trauma. Urology. 1989; 33: 215-8.

19. Griffith BC, Morey AF, Rozanski TA, Harris R, Dalton SR, Torgerson SJ, et al.: Central renal stab wounds: Treatment with augmented fibrin sealant in a porcine model. J Urol. 2004; 171: 445-7.

20. Cornum RL, Morey AF, Harris R, Gresham V, Daniels R, Knight RW, et al.: Does the absorbable fibrin adhesive bandage facilitate partial nephrectomy? J Urol. 2000; 164: 864-7.

21. Morey AF, Anema JG, Harris R, Gresham V, Daniels $\mathrm{R}$, Knight RW, et al.: Treatment of grade 4 renal stab wounds with absorbale fibrin adhesive bandage in a porcine model. J Urol. 2001; 165: 955-8.

22. Noller MW, Baughman SM, Morey AF, Auge BK: Fibrin sealant enables tubeless percutaneous stone surgery. J Urol. 2004; 172: 166-9.

23. Canby-Hagino ED, Morey AF, Jatoi I, Perahia B, Bishoff JT: Fibrin sealant treatment of splenic injury during open and laparoscopic left radical nephrectomy. J Urol. 2000; 164: 2004-5.

24. Evans LA, Ferguson KH, Foley JP, Rozanski TA, Morey AF: Fibrin sealant for the management of genitourinary injuries, fistulas and surgical complications. J Urol. 2003; 169: 1360-2.

25. Martinowitz U, Varon D, Jonas P, Bar-Maor A, Brenner B, Leibovitch I, et al.: Circumcision in hemophilia: 
the use of fibrin glue for local hemostasis. J Urol. 1992; 148: 855-7.

26. Riccabona M: Reconstruction or substitution of the pediatric urethra with buccal mucosa: indications, technical aspects and results. Tech Urol. 1999; 5: 133-8.

27. Ouwenga MK, Langston MD, Campbell SC: Use of fibrin sealant in recalcitrant Hemorrhagic cystitis. J Urol. 2004; 172: 1348.

28. Oosterlinck W, Cheng H, Hoebeke P, Verbeeck R: Watertight sutures with fibrin glue: an experimental study. Eur Urol. 1993; 23: 481-4.

29. Han SK, Kim SW, Kim WK: Microvascular anastomosis with minimal suture and fibrin glue: experimental and clinical study. Microsurgery. 1998; 18: 306-11.

30. Park W, Kim WH, Lee CH, Kim DY, Choi JH, Huh JW, et al.: Comparison of two fibrin glues in anastomoses and skin closure. J Vet Med A Physiol Pathol Clin Med. 2002; 49: 385-9.

31. McKay TC, Albala DM, Gehrin BE, Castelli M: Laparoscopic ureteral anastomosis using fibrin glue. J Urol. 1994; 152: 1637-40.

32. Wolf JS Jr, Soble JJ, Nakada SY, Rayala HJ. Humphrey PA. Clayman RV, et al.: Comparison of fibrin glue, laser weld, and mechanical suturing device for the laparoscopic closure of ureterotomy in a porcine model. J Urol. 1997; 157: 1487-92.

33. Patel R, Caruso RP, Taneja S, Stifelman M: Use of fibrin glue and gelfoam to repair collecting system injuries in a porcine model: implications for the technique of laparoscopic partial nephrectomy. J Endourol. 2003; 17: 799-804.

34. Eden CG, Sultana SR, Murray KH, Carruthers RK: Extraperitoneal laparoscopic dismembered fibringlued pyeloplasty: medium-term results. Br J Urol. 1997; 80: 382-9.

35. Morey AF, McDonough RC 3rd, Kizer WS, Foley JP: Drain-free simple retropubic prostatectomy with fibrin sealant. J Urol. 2002; 168: 627-9.

36. Diner EK, Patel SV, Kwart AM: Does fibrin sealant decrease immediate urinary leakage following radical retropubic prostatectomy? J Urol. 2005; 173: 1147-9.

37. Hick EJ and Morey AF: Initial experience with fibrin sealant in pendulous urethral reconstruction. Is early catheter removal possible? J Urol. 2004; 171: 1547-9.

38. Janetschek G, Hobisch A, Hittmair A, Holtl L, Peschel R, Bartsch G: Laparoscopic retroperitoneal lymphadenectomy after chemotherapy for stage IIB nonseminomatous testicular carcinoma. J Urol. 1999; 161: 477-81.
39. Chin AI, Ragavendra N, Hilborne L, Gritsch HA: Fibrin sealant sclerotherapy for treatment of lymphoceles following renal transplantation. J Urol. 2003; 170: 380-3.

40. Spotnitz WD, Falstrom JK, Rodeheaver GT: The role of sutures and fibrin sealant in wound healing. Surg Clin North Am. 1997; 77: 651-69.

41. Decastro BJ, Morey AF: Fibrin sealant for the reconstruction of fournier's gangrene sequelae. J Urol. 2002; 167: 1774-6.

42. Morris MS, Larson RJ, Santucci, RA, Morey AF: Role of fibrin sealant as tissue glue in complex genital reconstructive surgery. J Urol. 2004; 171: 19.

43. Gorodetsky R, Vexler A, An J, Mou X, Marx G: Haptotactic and growth stimulatory effects of fibrin(ogen) and thrombin on cultured fibroblasts. J Lab Clin Med. 1998; 131: 269-80.

44. Whelan C, Stewart J, Schwartz BF: Mechanics of wound healing and importance of Vacuum Assisted Closure in urology. J Urol. 2005; 173: 1463-70.

45. Morita T, Tokue A: Successful endoscopic closure of radiation induced vesicovaginal fistula with fibrin glue and bovine collagen. J Urol. 1999; 162: 1689.

46. Tsurusaki T, Sakai H, Nishikido M, Matsuya F, Kanetake H, Saito Y: Occlusion therapy for an intractable transplant-ureteral fistula using fibrin glue. J Urol. 1996; 155: 1698.

47. Christie RJ, Carrington L, Alving B: Postoperative bleeding induced by topical bovine thrombin: report of two cases. Surgery. 1997; 121: 708-10.

48. Pavlovich CP, Battiwalla M, Rick ME, Walther MM: Antibody induced coagulopathy from bovine thrombin use during partial nephrectomy. J Urol. 2001; 165: 1617.

49. Scheule AM, Beierlein W, Lorenz H, Ziemer G: Repeated anaphylactic reactions to aprotinin in fibrin sealant. Gastrointest Endosc. 1998; 48: 83-5.

50. MacGillivray TE: Fibrin sealants and glues. J Card Surg. 2003; 18: 480-4.

$$
\begin{array}{r}
\overline{\text { Accepted: }} \\
\text { September 30, } 2005
\end{array}
$$

